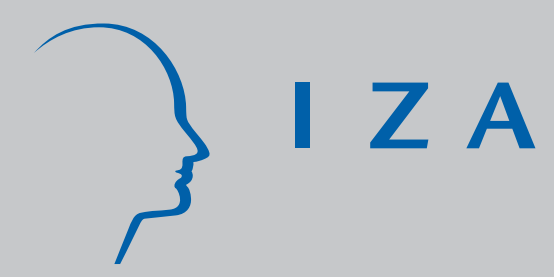

IZA DP No. 3033

Monetary Persistence, Imperfect Competition, and Staggering Complementarities

Christian Merkl

Dennis J. Snower

September 2007 


\title{
Monetary Persistence, Imperfect Competition, and Staggering Complementarities
}

\author{
Christian Merkl \\ Kiel Institute for the World Economy, \\ University of Kiel and IZA \\ Dennis J. Snower \\ Kiel Institute for the World Economy, \\ University of Kiel and IZA \\ Discussion Paper No. 3033 \\ September 2007 \\ IZA \\ P.O. Box 7240 \\ 53072 Bonn \\ Germany \\ Phone: +49-228-3894-0 \\ Fax: +49-228-3894-180 \\ E-mail: iza@iza.org
}

\begin{abstract}
Any opinions expressed here are those of the author(s) and not those of the institute. Research disseminated by IZA may include views on policy, but the institute itself takes no institutional policy positions.

The Institute for the Study of Labor (IZA) in Bonn is a local and virtual international research center and a place of communication between science, politics and business. IZA is an independent nonprofit company supported by Deutsche Post World Net. The center is associated with the University of Bonn and offers a stimulating research environment through its research networks, research support, and visitors and doctoral programs. IZA engages in (i) original and internationally competitive research in all fields of labor economics, (ii) development of policy concepts, and (iii) dissemination of research results and concepts to the interested public.
\end{abstract}

IZA Discussion Papers often represent preliminary work and are circulated to encourage discussion. Citation of such a paper should account for its provisional character. A revised version may be available directly from the author. 
IZA Discussion Paper No. 3033

September 2007

\section{ABSTRACT \\ Monetary Persistence, Imperfect Competition, and Staggering Complementarities}

This paper explores the influence of wage and price staggering on monetary persistence. We show that, for plausible parameter values, wage and price staggering are complementary in generating monetary persistence. We do so by proposing the new measure of "quantitative inertia," after discussing weaknesses of the "contract multiplier," a standard measure of monetary persistence. The existence of complementarities means that beyond understanding how wage and price staggering work in isolation, it is important to investigate their interactions. Furthermore, our analysis indicates that the degree of monetary persistence generated by wage vis-à-vis price staggering depends on the relative competitiveness of the labor and product markets. We show that the conventional finding that wage staggering generates more persistence than price staggering holds under homogenous capital accumulation. Under firm-specific capital, wage staggering generates more persistence only when the labor market is sufficiently competitive relative to the product market.

JEL Classification: E40, E50, E52

Keywords: monetary persistence, price staggering, wage staggering, firm-specific capital

Corresponding author:

Christian Merkl

Kiel Institute for the World Economy

Düsternbrooker Weg 120

24105 Kiel

Germany

E-mail: christian.merkl@ifw-kiel.de 


\section{$1 \quad$ Introduction $^{1}$}

We show in this paper that, for plausible parameter values, wage and price staggering are complementary in generating persistent output effects in response to monetary policy shocks. Specifically, their joint output effects of wage and price staggering is larger than the sum of the individual effects. It turns out that these complementarities are particularly important in the short-run and medium-run when monetary policy is most relevant. On a period-by-period basis, joint wage and price staggering can generate up to 20 percent more output than the sum of the individual staggering mechanisms. Complementarities show up more quickly and are more substantial under homogenous capital than under firm-specific capital accumulation. ${ }^{2}$ Clearly, the larger the complementarities between wage and price staggering are, the less important it is to know how wage and price staggering work in isolation and the more important it is to explore their interactions. This result deserves attention because, in practice, it is common for both nominal wages and prices to be set for finite periods of time. ${ }^{3}$

In the recent New Keynesian literature, a large body of articles argues that wage staggering generates more monetary persistence than price staggering in response to monetary policy shocks (i.e. the real effects of temporary monetary shocks are more persistent when wages are set through overlapping nominal contracts than when prices are set in this way), see e.g. Andersen (1998), Christiano et al. (2005), Huang and Liu (2002) and Kim (2003). ${ }^{4}$ We show that this result hinges significantly on the assumption of homogenous capital accumulation. ${ }^{5}$ Under firmspecific capital the relative strength of monetary persistence generated by wage vis-à-vis price staggering depends on the relative competitiveness of the labor and product markets.

The more competitive the product market is relative to the labor market, the more monetary persistence is generated by price staggering relative to wage staggering. We show that if the product market is sufficiently more competitive than

\footnotetext{
${ }^{1}$ We thank Guido Ascari, Franz Seitz, Roland Winkler, the participants of the IfW staff seminar, the Bundesbank-IWH Workshop on "Monetary and Financial Economics," and the Annual Meeting of the German Economic Association for very helpful comments.

${ }^{2}$ Under homogenous capital accumulation firms rent their capital from households, while they have to accumulate their own capital stock under firm-specific capital. Recently, there is very stimulating stream of literature which analyzes the implications of firm-specific capital. See, e.g., Altig et al. (2005), Sveen and Weinke (2005, 2007), and Woodford (2005)

${ }^{3}$ For medium scale business cyle models, which use both types of staggering, see, for example, Altig et al. (2005), Christiano et al. (2005), Smets and Wouters (2003).

${ }^{4}$ Chari et al.'s (2000) work is similar in spirit, although it does not model wage staggering. But it shows that price staggering cannot generate persistent output responses.

${ }^{5}$ In the papers which use a fixed capital stock, the result hinges on the constant returns to scale assumption (see Merkl and Snower, 2006).
} 
the labor market (under firm-specific capital), price staggering makes the real effects of temporary monetary shocks more persistent than does wage staggering. ${ }^{6}$ This result is potentially important because, in practice, product markets are often more competitive than labor markets. There are various obvious reasons for this, e.g. employers often find it more costly to switch between employees than consumers find it to switch between products.

In this context, it turns out to be useful to think carefully about how we measure monetary persistence. The effects of a temporary monetary shock on real economic activity through time (e.g. the effects of a temporary increase in money growth on national output) can be described by the relevant impulse response function (IRF). The "degree of monetary persistence" - however we choose to measure it - is a summary statistic of this function. The standard measure in the New Keynesian literature is the "contract multiplier," which measures the speed with which the response dies out, usually defined as the ratio of the response after the contract duration has elapsed to the response in the impact period (see e.g. Huang and Liu, 2002).

While the contract multiplier captures one feature of the IRF, it misses other important ones. Suppose, for example, that wage and price staggering were associated with IRFs that differed only by an multiplicative constant. This difference, however large, would not be identified by the contract multiplier, because the ratio of the response in any two periods would remain the same. To capture this difference, we use a measure that we call "quantitative inertia," which summarizes how much output changes, in total, after the monetary shock has disappeared. Specifically, for a temporary unit shock in period 0, quantitative inertia is defined to be the sum of the output responses from period 1 onwards. This measure of monetary persistence turns out to be particularly useful in describing how wage and price staggering affect monetary persistence and capturing the complementarities between wage and price staggering in generating monetary persistence.

The paper is organized as follows. Section 2 presents the underlying dynamic general equilibrium models. In order to understand the interactions between wage and price staggering, it is necessary to measure the individual effects and the joint effects of wage and price staggering on monetary persistence. Section 3 describes, formally and intuitively, how the relative strength of monetary persistence generated by wage vis-à-vis price staggering depends on the firm-specificity of capital

\footnotetext{
${ }^{6}$ Ascari (2003) and Edge (2002) point out the importance of factor specificity for monetary persistence. However, their analyses differ in several ways from ours. To show that price staggering can be equally persistent to wage staggering, they both abandon the homogenous labor market assumption, which we do not. In reaction to Chari et al.'s (2000) work, they both use Taylor contracts, while we employ Calvo contracts, which is more usual in recent business cycling modeling. Furthermore, Ascari (2003) models a fixed capital economy to obtain analytical results, while we model an endogenous capital stock.
} 
and the relative competitiveness of the labor and product markets. Section 4 derives the interactions between wage and price staggering in generating monetary persistence. Section 5 relates our results to the existing literature. Section 6 concludes.

\section{Models of Wage and Price Staggering}

Our model economies are of the standard New Keynesian variety, containing households, firms and a government. The government prints money and bonds and imposes taxes/transfers on the households. Wages and prices are staggered a la Calvo (1983). We examine the effects of a one time increase of the nominal money supply by $1 \%,{ }^{7}$ which is transferred from the monetary authority to the households in a lump-sum manner ("helicopter drop of money"). Households and firms do not know the shock until it occurs. We consider first wage staggering, then price staggering, and finally their joint effects.

\subsection{Wage Staggering}

\subsubsection{Firms}

Firms are monopolistic competitors. In the wage staggering model (with flexible prices) they can re-adjust their prices in each period. There is a fixed number of identical firms (normalized to unity), which face the following Cobb-Douglas production function: ${ }^{8}$

$$
Y_{t}(i)=A_{t} N_{t}(i)^{1-\alpha} K(i)^{\alpha},
$$

where $i$ is the index for the firm, $Y_{t}$ is the level of production, $A_{t}$ is a productivity parameter $^{9}, N_{t}$ is the labor input, $K_{t}$ is the capital input and $0<\alpha<1$. We assume firm-specific capital, i.e. each firm owns its own stock of capital which can

\footnotetext{
${ }^{7}$ In most other papers, which analyze the reaction to a money shock, the money growth follows an autoregressive process. We however do not consider autocorrelations of the money supply, as we seek to identify the endogenous persistence generated by the behavior of the model (rather than the persistence of the shocks). As Taylor noted, "leaving all the persistence of inflation to exogenous serial correlation is not a completely satisfactory conclusion" (Taylor, 1999: page $1040)$.

${ }^{8}$ We use the following terminology. Capital letters are level variables $\left(Y_{t}\right)$, lower case letters denote logarithmic variables $\left(y_{t}\right)$, letters with a bar $(\bar{y})$ denote the variable at the steady state and lower case variables with a hat $\left(\hat{y}_{t}\right)$ denote log-deviations from the steady state.

${ }^{9}$ In what follows we will normalize $A_{t}$ to 1 , as we are not interested in productivity shocks.
} 
be adjusted by changing the rate of investment (see e.g. Altig et al., 2005, Sveen and Weinke, 2005, 2007, Woodford, 2005). ${ }^{10}$

Prices are set flexibly as a mark-up over the nominal marginal costs:

$$
P_{t}(i)=\mu_{p} M C_{t}^{n}(i),
$$

where $P_{t}$ is the price ${ }^{11}, M C_{t}^{n}$ are the nominal marginal costs, $\mu_{p}=\left(\varepsilon_{p} /\left(\varepsilon_{p}-1\right)\right)$ is the steady-state mark-up in the product market, and $\varepsilon_{p}$ is the elasticity of substitution between different product types. The firm specific marginal costs are equal to the wage divided by the marginal product of labor:

$$
M C_{t}^{n}(i)=\frac{1}{(1-\alpha)} W_{t}\left(\frac{Y_{t}(i)}{K_{t}(i)}\right)^{\frac{\alpha}{1-\alpha}}
$$

We assume the same investment adjustment costs as in Christiano et al. (2005) and Smets and Wouters (2003):

$$
K_{t+1}(i)=(1-\delta) K_{t}(i)+\left(\left(1-S\left(\frac{I_{t}(i)}{I_{t-1}(i)}\right)\right) I_{t}(i)\right),
$$

where $I$ is investment and the function $S$ has the following properties: $S=S^{\prime}=0$, $S^{\prime \prime}>0$.

The intermediate goods firm maximizes the following problem:

$$
\max _{K_{t+j+1}, I_{t+j}} E_{t} \sum_{j=0}^{\infty} \beta^{j} \zeta_{t+j}\left[\begin{array}{c}
p_{t+j}(i) Y_{t+j}(i)-W_{t+j} N_{t+j}(i)-I_{t+j}(i)+ \\
\mu_{t+j}(i)\left(\begin{array}{c}
(1-\delta) K_{t+j}(i)+S\left(\frac{I_{t+j}(i)}{I_{t+j-1}(i)}\right) I_{t+j}(i) \\
-K_{t+j+1}(i)
\end{array}\right)
\end{array}\right]
$$

where $E$ is the expectations operator, $\beta$ is the discount factor, $\zeta_{t, t+j}$ and the $\mu_{t+j}$ are Lagrange multipliers, $p_{t+j}=P_{t+j}^{*}(i) / P_{t+j}$ is the firms' price divided by the aggregate price level, $W_{t+j}$ is the nominal aggregate wage level. We assume that investment goods can be bought at the same price as consumption goods, i.e. the final goods can either be used for capital accumulation or consumption. The firm faces a trade-off in its capital accumulation decision. Investment is costly, but reduces marginal labor costs by substituting capital for labor.

\footnotetext{
${ }^{10}$ For an economy with staggered wages and flexible prices, the assumption of firm-specific capital leads to the same results as homogenous capital because there is no heterogeneity across firms. However, the results differ substantially when price staggering comes into play (due to firm-specific marginal costs).

${ }^{11}$ The individual prices are aggregated à la Dixit-Stiglitz (1977). See Section 2.2. For brevity, we omit the final goods producer in the model setup under flexible prices. The relative price of different goods types does not vary, i.e. the product bundle (bought by the representative household) is the same in each period.
} 
The capital and investment first-order conditions are: ${ }^{12}$

$$
\begin{gathered}
\mu_{t}(i)=\frac{\beta \zeta_{t+1}}{\zeta_{t}}\left(R_{t+1}^{k, r}(i)+\mu_{t+1}(i)(1-\delta)\right), \\
-\zeta_{t}+\zeta_{t} \mu_{t}(i)\left[1-S\left(\frac{I_{t}(i)}{I_{t-1}(i)}\right)\right]-\zeta_{t} \mu_{t}(i) \frac{I_{t}(i)}{I_{t-1}(i)} S^{\prime}\left(\frac{I_{t}(i)}{I_{t-1}(i)}\right)+ \\
\beta \zeta_{t+1} \mu_{t+1}(i) S^{\prime}\left(\frac{I_{t+1}(i)}{I_{t}(i)}\right)\left(\frac{I_{t+1}(i)}{I_{t}(i)}\right)^{2}=0
\end{gathered}
$$

where $R_{t+1}^{k, r}$ is the real shadow rental rate of capital, which is defined as follows:

$$
R_{t}^{k, r}(i)=\left(\frac{\alpha}{1-\alpha}\right) \frac{W_{t}}{P_{t}}\left(\frac{Y_{t}(i)}{K_{t}(i)}\right)^{\frac{1}{1-\alpha}}
$$

\subsubsection{Households}

Aggregation: The aggregate labor input is a Dixit-Stiglitz function of a continuum of individual labor inputs (normalized to unity):

$$
N_{t}=\left[\int_{h^{\prime}=0}^{1} N_{t}\left(h^{\prime}\right)^{\frac{\varepsilon_{w}-1}{\varepsilon_{w}}} d h^{\prime}\right]^{\frac{\varepsilon_{w}}{\varepsilon_{w}-1}}
$$

where $N_{t}(h)$ is the amount of labor chosen from household $h$ and $\varepsilon_{w}$ is the elasticity of substitution between different labor types.

Minimizing the firm's labor cost, we obtain its labor demand function for each labor type:

$$
N_{t}(h)=\left(\frac{W_{t}^{*}(h)}{W_{t}}\right)^{-\varepsilon_{w}} N_{t}
$$

where $W_{t}^{*}(h)$ is the optimal wage set by household $h$ in period $t$. The corresponding aggregate wage index $W_{t+i}$ is defined as $W_{t}=\left[\int_{h^{\prime}=0}^{1} W_{t}\left(h^{\prime}\right)^{1-\varepsilon_{w}} d h^{\prime}\right]^{\frac{1}{1-\varepsilon_{w}}}$.

The household's instantaneous utility is $U\left(C_{t}(h)\right)-V\left(N_{t}(h)\right)+Z\left(M_{t}(h) / P_{t+j}\right)$, $U^{\prime}, V^{\prime}, Z^{\prime}>0, U^{\prime \prime}, Z "<0, V^{\prime \prime}<0$, where $C_{t}(h)$ is its consumption, ${ }^{13} N_{t}(h)$ is its employment, and $M_{t}(h) / P_{t}$ are its real money balances. In each period the wages can be reset with probability $\left(1-\theta_{w}\right)$.

The household maximizes the following specific utility function in a Calvo setting:

\footnotetext{
${ }^{12}$ For the derivation of these and further results see the Technical Appendix in Merkl and Snower (2007).

${ }^{13}$ As usual in the literature, we assume complete insurance markets that allow households to share the income risk stemming from staggered wage setting.
} 


$$
U\left(C_{t}(h), \frac{M_{t}(h)}{P_{t}}, N_{t}(h)\right)=\frac{C_{t}^{1-\sigma}(h)}{1-\sigma}+\frac{\left(\frac{M_{t}(h)}{P_{t}}\right)^{1-\nu}}{1-\nu}-\frac{N_{t}^{1+\varphi}(h)}{1+\varphi},
$$

subject to its budget constraint:

$$
\begin{aligned}
& E_{t} \sum_{i=0}^{\infty} \beta^{j}\left(C_{t+j}+\frac{R_{t+j}^{-1} B_{t+j}+M_{t+j}}{P_{t+j}}\right)= \\
& E_{t} \sum_{j=0}^{\infty} \beta^{j}\left[\frac{W_{t}(h)}{P_{t+j}} N_{t+j}(h)+\frac{T_{t+j}}{P_{t+j}}+\frac{\Pi_{t+j}}{P_{t+j}}+\frac{B_{t+j-1}}{P_{t+j}}+\frac{M_{t+j-1}}{P_{t+j}}\right],
\end{aligned}
$$

where $R_{t+j}=1+r_{t+j}$ is the discount factor on its one-period bond holdings $B_{t+j}$, $T_{t+j}$ is its net lump-sum transfers from government, and $\Pi_{t+j}$ is its profit income.

The household's decision can be decomposed into two optimization problems. First, the "inter-contract problem" (wage decision) which only takes place with probability $\left(1-\theta_{w}\right)$ in each period. Here the utility function is maximized with respect to the optimal wage. Second, the "intra-contract problem" in which the contract wage is given and the household maximizes its utility with respect to its other endogenous variables (consumption, money and bond holdings) each period.

The Inter-Contract Problem: Solving the inter-contract problem, we obtain the following optimal wage $\left(W_{t}^{*}(h)\right)$ :

$$
W_{t}^{*}(h)=\mu_{w} \frac{E_{t} \sum_{j=0}^{\infty}(\beta \theta)^{j}\left[-V_{N}\left(N_{t+j}^{d}(h)\right)\right] N_{t+j}^{d}(h)}{E_{t} \sum_{j=0}^{\infty}(\beta \theta)^{j}\left[\frac{U_{c}\left(C_{t+j}\right)}{P_{t+j}}\right] N_{t+j}^{d}(h)},
$$

where $\mu_{w}=\left(\varepsilon_{w} /\left(\varepsilon_{w}-1\right)\right)$ is the steady state mark-up in the labor market and $V_{N}, U_{c}$ are the first derivatives of the utility function with respect to labor and consumption. The intuition of the formula (13) is easier to grasp in the loglinearized form:

$$
\hat{w}_{t}^{*}(h) \approx(1-\beta \theta) E_{t} \sum_{j=0}^{\infty}(\beta \theta)^{j}\left(\widehat{m r} s_{t, t+j}(h)+\hat{p}_{t+j}\right) .
$$


Households set their nominal wage as a mark-up ${ }^{14}$ over the weighted average ${ }^{15}$ of the marginal rate of substitution ${ }^{16}$ between labor and consumption $\left(M R S_{t, t+j}(h)\right.$ $\left.=-V_{N}\left(N_{t+j}(h)\right) / U_{c}\left(C_{t+j}\right)\right)$ and the price level.

In the Calvo wage-staggering model, households solve an intertemporal utility maximization problem, taking into account the probability that future wages cannot be re-set. ${ }^{17}$ In case of a shock, a fraction of households will not be able to reset the wages immediately and this may have implications for employment. Although Barro (1977) and others have written that it is inefficient to set wages and employment independently, it is very uncommon in practice for employers to make their employment decision in conjunction with their employees. ${ }^{18}$

If firms did not make employment decisions unilaterally but shared this decision with their employees, the employees would be involved in the firing of their colleagues. This may create uncooperative behavior in teams and thereby reduce the productivity of the workforce (see e.g. Lindbeck and Snower, 1988). Furthermore, Dobson (1997) provides a rent-seeking rationale for a "right-to-manage" framework for employment decisions.

The Intra-Contract Problem: For the intra-contract problem we obtain the following specific first order conditions:

$$
\left(\frac{E_{t} C_{t+1}}{C_{t}}\right)^{\sigma}=\beta R_{t} \frac{P_{t}}{E_{t} P_{t+1}}
$$

and

$$
\frac{\left(M_{t} / P_{t}\right)^{-v}}{C_{t}^{-\sigma}}=1-R_{t}^{-1}
$$

Finally, we close the system with a goods market clearing condition and a money supply equation:

$$
Y_{t}=C_{t}+I_{t},
$$

\footnotetext{
${ }^{14}$ Note that the constant mark-up drops out due to the log-linearization.

${ }^{15}$ Using the discount rate and the probability that wage contracts cannot be re-set in the future.

${ }^{16} \widehat{\mathrm{mrs}}_{t, t+i}(h)$ denotes the log-linearized marginal rate of substitution of household $h$ in period $t+i$ where the last wage setting took place in period $t$.

${ }^{17}$ The microeconometric literature, surveyed by Taylor (1999), for example, finds that workers set their wages for pre-specified time intervals (although the time frequency depends somewhat on the study) and that wage setting dates are staggered.

${ }^{18}$ See for example Oswald (1993) for survey evidence and Erceg et al. (2000) who also discuss this issue.
} 


$$
\frac{M_{t}}{M_{t-1} \pi_{t}}=\varepsilon_{t}
$$

where $\varepsilon_{t}$ is the monetary shock.

\subsubsection{The Log-Linearized System}

After log-linearizing the equations above, we obtain the following system of equations, where equations (19) - (25) are the same for price staggering, wage staggering and joint price and wage staggering. ${ }^{19}$

Shadow value of capital: $\hat{\mu}_{t}=\beta(1-\delta) \hat{\mu}_{t+1}+(1-\beta(1-\delta)) \hat{r}_{t+1}^{k, r}-\left(\hat{r}_{t}-\hat{\pi}_{t+1}\right)$, where $\hat{r}_{t}^{k, r}=\hat{w}_{t}-\hat{p}_{t}+\frac{1}{1-\alpha}\left(\hat{y}_{t}-\hat{k}_{t}\right)$.

Investment adjustment: $\hat{\mu}_{t}=S^{\prime \prime}\left(\hat{\imath}_{t}-\beta \hat{\imath}_{t-1}\right)-\beta S^{\prime \prime}\left(\hat{\imath}_{t+1}-\beta \hat{\imath}_{t}\right)$.

$$
\text { Capital trajectory: } \hat{k}_{t+1}=(1-\delta) \hat{k}_{t}+\delta \hat{\imath}_{t} \text {. }
$$

$$
\text { Production function: } \hat{y}_{t}=\alpha \hat{k}_{t}+(1-\alpha) \hat{n}_{t},
$$

where $\hat{y}_{t}=\gamma_{c} \hat{c}_{t}+\gamma_{i} \hat{\imath}_{t}, \gamma_{c}$ and $\gamma_{c}$ are the consumption and the investment share of output respectively $\left(\gamma_{i}=\frac{\alpha \delta}{\mu_{p}(\delta-\ln \beta)}, \gamma_{c}=1-\gamma_{i}\right)$.

Households' Euler equation: $\hat{c}_{t}=E_{t}\left(\hat{c}_{t+1}\right)-\frac{1}{\sigma}\left(\hat{r}_{t}-E_{t}\left(\hat{\pi}_{t+1}\right)\right)$.

$$
\text { Money demand: } \hat{m}_{t}-\hat{p}_{t}=\frac{\sigma}{\nu} \hat{c}_{t}-\eta \hat{r}_{t},
$$

where the corresponding money supply is $\hat{m}_{t}-\hat{\pi}_{t}=\hat{m}_{t-1}+\varepsilon_{t}$ and $\eta=\frac{1}{\bar{r} \nu}$.

$$
\text { Price setting: } \hat{p}_{t}=\hat{w}_{t}+\frac{\alpha}{1-\alpha}\left(\hat{y}_{t}-\hat{k}_{t}\right) \text {. }
$$

$$
\begin{array}{ll}
\text { Wage staggering : } \quad & \left.\beta \theta_{w} E_{t} \hat{w}_{t+1}=\left(1+\beta \theta_{w}^{2}-\frac{\varphi \epsilon_{w}}{\left(1+\varphi \epsilon_{w}\right)}\left(1-\theta_{w}\right)\left(1-\beta \theta_{w}\right)\right) 2(6)\right) \\
& -\theta_{w} \hat{w}_{t-1}-\frac{1}{\left(1+\varphi \epsilon_{w}\right)}\left(1-\theta_{w}\right)\left(1-\beta \theta_{w}\right)\left(\sigma \hat{c}_{t}+\varphi \hat{n}_{t}+\hat{p}_{t}\right) .
\end{array}
$$

\footnotetext{
${ }^{19}$ The index $i$, which denotes firm-specific values, can be omitted in the model with flexible prices, as all firms behave symmetrically.
} 


\subsection{Price Staggering}

Labor is a homogeneous factor and households set their wage in each period. Firms set the price (in staggered manner) as a mark-up over marginal costs.

\subsubsection{Firms}

Final Goods Producer: For analytical convenience we introduce a final goods producer who is a perfect competitor and bundles a final consumption good $Y_{t}$, by minimizing the cost of consumption of the different product varieties for a given consumption bundle:

$$
Y_{t}=\left[\int_{i^{\prime}=0}^{1} Y_{t}\left(i^{\prime}\right)^{\frac{\varepsilon_{p}-1}{\varepsilon_{p}}} d i^{\prime}\right]^{\frac{\varepsilon_{p}}{\varepsilon_{p}-1}}
$$

Thus, we obtain the following product demand function:

$$
Y_{t}(i)=\left(\frac{P_{t}^{*}(i)}{P_{t}}\right)^{-\varepsilon_{p}} Y_{t}
$$

where $P_{t}^{*}(i)$ is the optimal price set by firm $i$. The corresponding aggregate price index is $P_{t}$ is defined as $P_{t}=\left[\int_{i^{\prime}=0}^{1} P_{t}\left(i^{\prime}\right)^{1-\varepsilon_{p}} d i^{\prime}\right]^{\frac{1}{1-\varepsilon_{p}}}$.

Intermediate Goods Producer: In each period firms reset their price with probability $\left(1-\theta_{p}\right)$. Firms maximize their profits:

$$
\max _{K_{t+j+1}, I_{t+j}} E_{t} \sum_{j=0}^{\infty} \beta^{j} \zeta_{t+j}\left[\begin{array}{c}
p_{t+j}(i) Y_{t+j}(i)-W_{t+j} N_{t+j}(i)-I_{t+j}(i)+ \\
\mu_{t+j}\left(\begin{array}{c}
(1-\delta) K_{t+j}(i)+S\left(\frac{I_{t+j}(i)}{I_{t+j-1}(i)}\right) I_{t+j}(i)- \\
K_{t+j+1}(i)
\end{array}\right)
\end{array}\right]
$$

Note that we obtain the same capital and investment first order conditions as above (see equations (7) and (6)). However, under price staggering all these variables are firm-specific.

To obtain the price setting equation, the firm-specific capital stocks have to be accumulated nonlinearly. Altig et al. (2005) show that the log-linearized Phillips curve looks as follows:

$$
\hat{\pi}_{t}=\beta E_{t} \hat{\pi}_{t+1}+\kappa \widehat{m c_{t}^{r}}
$$


where $\kappa=\chi \lambda_{p}, \lambda_{p}=\left[\left(1-\theta_{p}\right)\left(1-\beta \theta_{p}\right)\right] / \theta_{p}$ is the coefficient we obtain under homogenous capital, and $\chi$ is an additional coefficient that arises due to firmspecific capital (a function of the capital accumulation). Altig et al. (2005) show that all other equations in the firm-specific capital model are the same as under homogenous capital.

\subsubsection{Households}

As households can re-set the wage every period in the price-staggering model, their optimality problem reduces to the intra-contract optimization problem of the wage-staggering model above. Thus, we obtain the following static wage setting equation:

$$
\frac{W_{t}}{P_{t}}=-\frac{U_{N_{t}}}{U_{C_{t}}}=\mu_{w} C_{t}^{\sigma} N_{t}^{\varphi}
$$

\subsubsection{The Log-Linearized System}

The price-staggering model is described by equations (19) - (24), the Phillips curve (30), and the following two log-linearized equations:

$$
\begin{gathered}
\hat{w}_{t}-\hat{p}_{t}=\sigma \hat{c}_{t}+\varphi \hat{n}_{t} . \\
\widehat{m c_{t}^{r}}=\hat{w}_{t}-\hat{p}_{t}+\frac{\alpha}{1-\alpha}\left(\hat{y}_{t}-\hat{k}_{t}\right)
\end{gathered}
$$

\section{Capital Specificity, Competition, and Mone- tary Persistence}

We consider monetary persistence in response to a one-off money growth shock. In particular, suppose that money growth is initially zero, then in period 0 it increases to some positive constant (normalized to unity), and thereafter it returns to zero.

\subsection{The Conventional Case}

We simulate the impulse response functions (IRFs) of the deviation of output from the steady state under wage and price staggering with respect to a one-off $1 \%$ money growth shock, for the following standard parameter values ${ }^{20}$ :

\footnotetext{
${ }^{20}$ In addition, the elasticity of substitution in the labor market is varied, which is discussed later.
} 


\begin{tabular}{||l||l||l||l||}
\hline \hline$\theta_{w}=0.5$ & $\theta_{p}=0.5$ & $\alpha=0.33$ & $\delta=0.025$ \\
\hline \hline$\varphi=1$ & $\nu=1$ & $\sigma=1$ & $S^{\prime \prime}=3$ \\
\hline \hline$\beta=0.99$ & $\varepsilon_{w}=10$ & $\varepsilon_{p}=10$ & $\kappa=0.04$ \\
\hline \hline
\end{tabular}

Table 1: Calibration Values

The value for $\theta_{p}$ and $\theta_{w}$ implies that prices and wages are set every two quarters, on average (see, e.g., Bils and Klenow, 2004). As usual in the literature, we set $\alpha=0.33$, which is the standard value (corresponding to a two thirds labor share of income under perfect competition). By setting $\sigma=1$, we obtain a logarithmic utility function for consumption. Furthermore, we choose $\nu=1$. The disutility of labor is quadratic $(\varphi=1)$. By setting $\beta=0.99$, we obtain a quarterly real discount rate of $1 \%$, i.e. about $4 \%$ a year, as it is standard in the literature.

The value for $\varepsilon_{p}$ implies a steady state mark-up of about $11 \%$ over marginal costs, whereas the interpretation for $\varepsilon_{w}$ is somewhat more difficult, it is the markup over marginal rate of substitution between work and consumption. ${ }^{21}$ For the moment we assume that $\varepsilon_{w}=\varepsilon_{p}$ and set them both to 10 , as it is common in the literature (see e.g. Kim, 2003), although there is no empirical literature that would give explicit support for this assumption.

We set the quarterly depreciation rate $(\delta)$ to $2.5 \%$, which is the most common value observed in the literature (see e.g. Christiano et al., 2005). The second derivative of the investment adjustment costs $\left(S^{\prime \prime}\right)$ is set to 3 , which corresponds to the benchmark estimation by Altig et al. (2005).

In order to make our results comparable to the existing literature (Chari et al., 2000, Christiano et al., 2005, Huang and Liu, 2002, Kim, 2003), we begin by assuming that capital is homogeneous. ${ }^{22}$ Under this standard assumption, we obtain the conventional finding, namely that the output response dies out more slowly under wage staggering than under price staggering. Existing studies commonly use the contract multiplier to evaluate persistence (Huang and Liu, 2002). ${ }^{23}$ This measures the "speed of dying out" (SDO), i.e. the output effect in the first after-shock period (as the contract duration is two under our calibration) divided by the impact effect (the output effect in period 0). For the calibration above, we obtain a speed of dying out of $38 \%$ for price staggering, whereas it is $82 \%$ for wage staggering (see Figure 1 for an optical inspection). This result corresponds to Christiano et al. (2005) and Kim (2003) who write that wage

\footnotetext{
${ }^{21}$ For a discussion of the role of the marginal rate of substitution, see e.g. Gali et al. (2003).

${ }^{22}$ Under homogenous capital $\chi=1$.

${ }^{23}$ Chari et al. (2000, p. 1152) use a somewhat different version of the contract multiplier, defined as: "half life of output in the model with staggered price setting to the half life of output under synchronized price setting." All these measure have in common that they measure the speed of dying out of the impulse response function.
} 
staggering generates more persistent output responses than price staggering (under homogenous capital). ${ }^{24}$

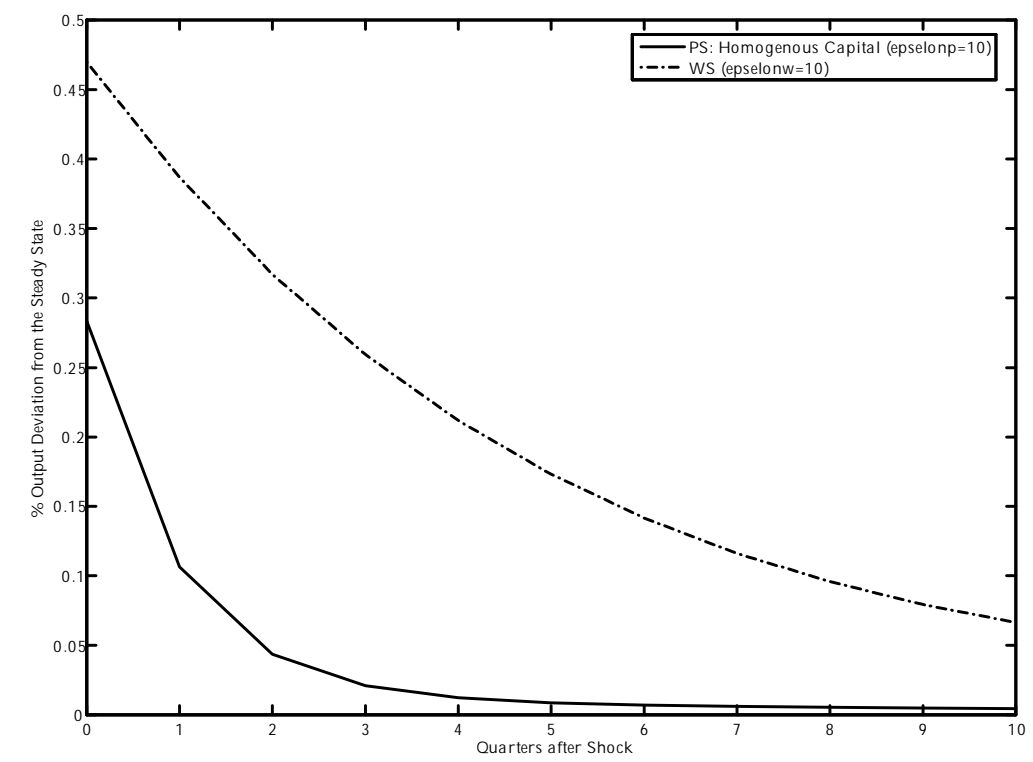

Figure 1: Relative persistence of wage and price staggering under homogenous capital accumulation.

\subsection{Firm-Specific Capital and Persistence}

Altig et al. (2005), Eichenbaum and Fisher (2004), Woodford (2005) note that the assumption of homogenous capital has unrealistic implications in the New Keynesian models. ${ }^{25}$ Thus, in what follows, we assume that there is firm-specific capital, i.e. that each firm allocates and depreciates its own capital stock. Moving from homogenous to firm-specific capital has no influence on the corresponding monetary persistence under wage staggering. ${ }^{26}$ Under price staggering, by contrast,

\footnotetext{
${ }^{24}$ If we choose a more realistic elasticity of substitution for the labor market (corresponding to Huang and Liu, 2002), the difference would be reduced (see Figure 2 for the wage-staggering IRFs with less competitive markets and the second row of Table 2), but the conventional result still holds.

${ }^{25}$ Altig et al. (2005: page 2) write that homogenous capital is "empirically unrealistic but defended on the grounds of tractability. The hope is that these assumptions are innocuous and do not affect major model properties. In fact these assumptions matter a lot."

${ }^{26}$ If prices are set flexibly, all firms have the same homogenous capital stock. See Section 2 for details.
} 
monetary persistence rises substantially when we move from homogenous to firmspecific capital. Altig et al. (2005) estimate the $\kappa$ coefficient of the Phillips curve to be 0.04 , which is consistent with an average price duration of two quarters under price staggering and firm-specific capital. ${ }^{27}$ The associated speed of dying out is $84 \%$ (instead of $38 \%$ under homogenous capital)

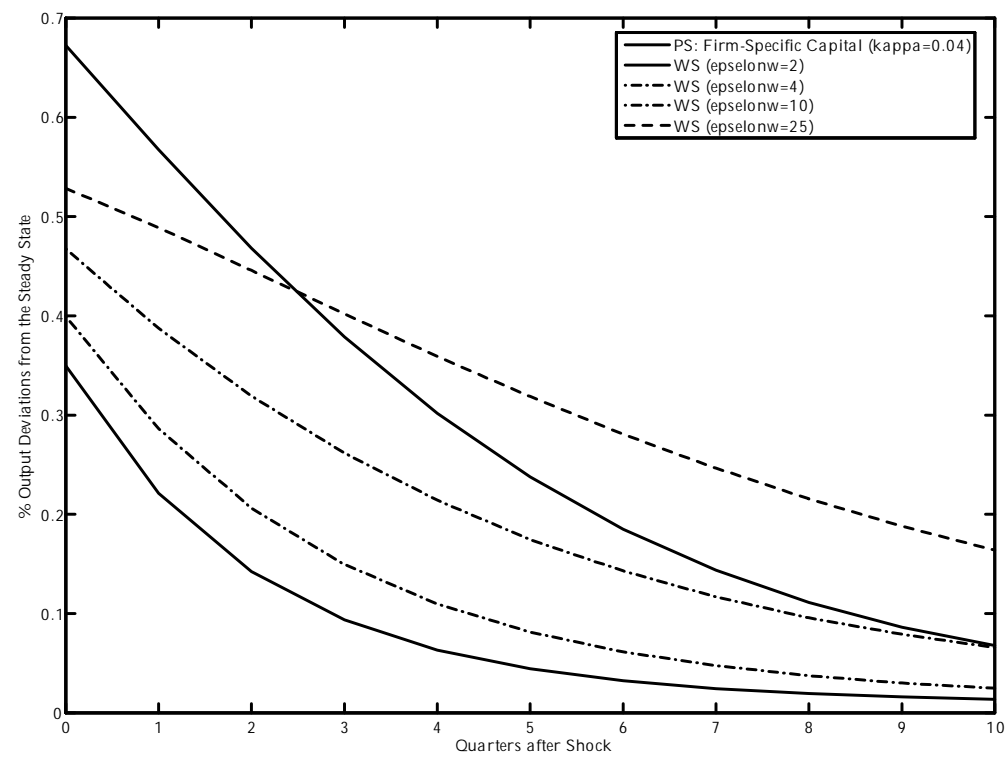

Figure 2: Results for different labor market structures under firm-specific capital.

If the market structure is the same in the product and labor market, then the move from homogenous to firm-specific capital implies that the difference in monetary persistence between wage and price staggering shrinks. Specifically, setting the elasticity of substitution in the labor market to the same level as in the product market $\left(\varepsilon_{w}=25\right)$, wage staggering generates slightly more persistence

\footnotetext{
${ }^{27}$ This $\kappa$ is reconcilable with homogenous capital only if price setters readjust their prices no more than about every six quarters, while it is consistent with a price duration of about two quarters under firm-specific capital. The exact price duration depends on the elasticity of substitution in the product market. While a low mark-up $\left(\mu_{p}=1.01\right)$ implies that price are re-set somewhat more frequently than every second quarter $(1.5)$, an intermediate mark-up $\left(\mu_{p}=1.04\right)$ means that firms re-set their prices every 2.2 quarters on average (see Altig et al., 2005). For our calibration, the implications are minor and do not change the major model properties, as they only affect the consumption share $\left(\gamma_{c}\right)$. For the results below, we use an elasticity of substitution in the product market $\left(\varepsilon_{p}\right)$ of 25 , as it corresponds to Bowman's (2003) estimations.
} 
than price staggering (see Figure 2) in terms of the speed of dying out (93\% versus $84 \%)$.

However, the market structure is not necessarily the same in the product and labor market. Instead, as argued below, we have reason to believe that product markets are often more competitive than labor markets and in that case, price staggering can generate more monetary persistence than wage staggering. We now proceed to demonstrate this result, which calls into question the standard finding that wage staggering always leads to more persistence than price staggering.

\subsection{Competition and Persistence}

\subsubsection{Numerical Results}

For a variety of reasons, product markets are commonly more competitive than labor markets. This is certainly true in the presence of centralized wage bargaining, since centralized price bargaining is uncommon. But even in the absence of centralized wage bargaining, wage setting often tends to be more centralized than price setting: workers of comparable types in an enterprise or firm often set their wages at the same time, whereas such synchronization generally does not apply to substitutable products across the economy. Consequently, firms' costs of switching among standard labor types tends to be substantially greater than consumers' costs of switching among standard product types.

For simplicity, we capture the degree of competition in the product and labor markets by the elasticities of substitution among products (in household consumption) and among labor types (in firm production), respectively. The greater the product elasticity of substitution, the lower is the mark-up of prices over marginal cost (Lerner's index of monopoly power); the greater the labor elasticity of substitution, the lower is the mark-up of wages over the marginal rate of substitution between labor and consumption.

It turns out that the relative degrees of competition in the product and labor markets (viz., the relative elasticities of substitution) play an important role in determining the relative magnitudes of monetary persistence generated by wage and price staggering. While we set $\varepsilon_{p}=25$ for the economy with price staggering and firm-specific capital, for wage staggering we now consider the following alternative elasticities of substitution for the labor market: $\varepsilon_{w}=2,4,10 .^{28}$

\footnotetext{
${ }^{28}$ Microeconomic evidence shows that the elasticities of substitution among different labor types are quite low. Griffin's (1992) estimate for the elasticity of substitution between white males and females as well as for white males and black males are e.g. roughly 3 . We are in line with Huang and Liu (2002), who - in contrast to many other authors - use different values for the elasticities of substitution of wage and price staggering. They set $\varepsilon_{w}$ equal to 2,4 and 6 alternatively.
} 
Eyeballing Figure 2, we are driven to call into question the standard result that wage staggering can generally generate more persistence than price staggering (see Andersen, 1998, Christiano et al., 2005, Huang and Liu, 2002, Kim, 2003). Although the output IRF for wage staggering dies out somewhat more slowly under the same market structure in the product and labor markets (i.e. same elasticity of substitution; see Table 2), it starts at a much lower output level. The contract multiplier captures the relative change in the slope of the IRFs, but not the relative positions of these IRFs. If the wage- and price-staggering IRFs had the same slope, but the wage setting IRF were much lower, then the wage- and price-setting responses would have the same contract multiplier, but we would clearly like to say that the output response under wage setting is in some sense more persistent than that under price setting.

\subsubsection{Quantitative Inertia: An Alternative Measure of Monetary Per- sistence}

On this account, we propose a different output persistence measure, called "quantitative inertia" (QI). It is the sum of all output changes from period 1 to period $\tau$, due to a one-off, period-0, unit monetary shock:

$$
\psi_{\tau}=\sum_{t=1}^{\tau} \hat{y}_{t}
$$

where $\hat{y}_{t}$ is the difference between output in the presence and absence of the shock (deviations from the steady state). For the moment, we consider a long-run measure of quantitative inertia by setting $\tau=\infty$. (By contrast, when we evaluate complementarities between wage and price staggering in Section 4, we will also consider shorter-run measures by setting $\tau$ to some finite value.)

Although the speed of dying out and quantitative inertia convey the same information if the IRF follows a first order autoregressive process, this is not true for higher order processes. The former tells us about the speed of dying out in the immediate after-math of the shock, while the latter conveys information about the amount of additional output that is produced once the shock has disappeared. As noted, if the IRF is shifted by a multiplicative amount, a speed-of-dying-out measure would indicate no change in persistence, while the quantitative inertia measure shows that the output effects in the aftermath of the shock have increased. ${ }^{29}$ Note further that if the speed of dying out varies over time (as it is the case in our models), measures which are associated with it (such as the contract

\footnotetext{
${ }^{29}$ The quantitative inertia measure brings about another advantage. Measures such as the half-life or contract multiplier are not defined when, on account of delayed adjustments, there is no reaction during the shock period. Christiano et al. (2005, p. 42) are aware of this problem and define an alternative measure: "the percentage of the positive output response that occurs after
} 
multiplier or the half-life) are very much dependent on time period over which they are defined. ${ }^{30}$

Using quantitative inertia as measure of persistence from wage and price staggering (WS and PS respectively in Table 2) and setting $\tau=\infty$, we find that the relative market structure in the product and labor markets matters a lot. Under firm-specific capital, price staggering generates larger output effects than wage staggering once the shock has disappeared, provided that we make the plausible assumption that the labor market is less competitive than the product market (see Table 2). Quantitative inertia does not tell the same story about the relative persistence of wage and price staggering as the speed of dying out (SDO, see Table 2 ). This is very obvious for the numerical example with $\varepsilon_{w}=10$, which delivers roughly the same speed of dying out as price staggering under firm-specific capital. However, the quantitative inertia is much larger under price staggering (and firmspecific capital) than under wage staggering. This important feature of monetary persistence has so far been ignored in the literature. ${ }^{31}$

\begin{tabular}{||l||l||l||l||l||l||}
\hline \hline & PS: firm-specific $(\kappa=0.04)$ & WS: $\varepsilon_{w}=2$ & $\varepsilon_{w}=4$ & $\varepsilon_{w}=10$ & $\varepsilon_{w}=25$ \\
\hline \hline QI & 3.38 & 0.87 & 1.35 & 2.54 & 4.74 \\
\hline \hline SDO & 0.84 & 0.63 & 0.72 & 0.83 & 0.93 \\
\hline \hline
\end{tabular}

Table 2: Monetary Persistence

\subsection{Intuition}

\subsubsection{The Conventional Intuition}

The conventional intuition on why monetary persistence is greater under wage staggering than under price staggering may be summarized as follows. ${ }^{32}$ Suppose that there is homogenous capital. Under price staggering households set their

the typical contract in place at the time of the shock has been reoptimized." This measure can be considered as a mixture between the typical speed of dying out measure and our quantitative inertia measure. Note however that, as this measure is also a ratio between two (cumulative) parts of the IRF and does not capture IRF shifts, it turns out that Christiano et al.'s (2005) measure would not be well suited to explore complementarities.

${ }^{30}$ See Appendix and Figure 5 for further details.

${ }^{31}$ It is known that with factor specificity wage and price staggering can generate similar degrees of persistence (Ascari, 2004, Edge, 2003). However, the focus in the literature was so far largely on labor market segmentation. Ascari (2003, p. 527) writes that "only models with some form of labour immobility could potentially deliver a substantial degree of persistence." Under labor market segmentation (i.e. labor is specific to one firm) price staggering would become even more persistent in our model. This result is very nicely illustrated by equations (31) and (35) in Huang and Liu (2002).

${ }^{32}$ See Huang and Liu (2002) for a more detailed description. 
wages as mark-up over the current marginal rate of substitution. As the households' wage decision is synchronized, wages adjust quickly. They even overshoot their new steady state level, since the positive output effect during the initial periods after the shock increases the marginal disutility of labor and thus raises the marginal rate of substitution between work and consumption. In response, firms raise their prices quickly, since these prices are a constant mark-up over current and future marginal costs. Most importantly, under homogenous capital accumulation $^{33}$ the marginal costs do not depend on the firm-specific output (i.e. the marginal cost curve is flat) and as a consequence, firms will adjust their prices quickly (see discussion of diminishing returns below).

Under wage staggering, a positive monetary shock raises employment and, with it, the disutility of labor, and thus each household has an incentive to push the wage up. But an increase in the individual wage also raises the household's wage relative to other wagesetting cohorts (as the marginal rate of substitution is household specific), leading to a fall in the demand for the household's labor. These wage adjustments are moderate, however, since households dislike fluctuations in their working hours over time (as the marginal disutility of labor rises with hours employed $\left.^{34}\right)$.

Thus, in contrast to the price-staggering model, there is a gradual rise in wages, rather than overshooting. This leads to slower price adjustments by firms, even though prices can be adjusted instantaneously. The slower price adjustment leaves more room for output deviations from the steady state. Consequently wage staggering delivers more output persistence than does price staggering.

\subsubsection{Intuition on How Diminishing Returns Affect Monetary Persis- tence}

Under firm-specific capital accumulation (or under a fixed capital stock with diminishing returns to labor ${ }^{35}$ ), marginal costs are not constant across firms, but depend positively on the firms' output. When there is a positive monetary shock in the price-staggering model, then (as above) households adjust their wages upwards instantaneously and wages overshoot their long-run equilibrium. This leads to a rise in average marginal costs for the economy. Thus each firm has an incentive to raise its price. When it does, its price rises relative to other prices at the beginning of the contract period (while it falls if the firm cannot adjust the price for a while). As households substitute between different product types, the firm-specific demand varies over time and the firm-specific marginal costs move

\footnotetext{
${ }^{33}$ The same is true under a fixed capital stock and constant returns to labor (see previous version of this paper which is available on request).

${ }^{34}$ The disutility of labor is quadratic in our calibration.

${ }^{35}$ The fixed capital model with diminishing returns was first modeled by Sbodorne (2002).
} 
relative to other marginal costs. Due to these variations in firm-specific marginal costs, the firm's price increase will be less (as the firm dislikes fluctuations in firmspecific marginal costs) than it would have been if all firms had the same marginal cost schedule. The steeper the firm-specific marginal costs are (i.e. the faster the firm-specific returns to labor diminish), the more moderate the price adjustment will be. ${ }^{36}$ Thus the adjustment path from the old to the new steady takes a longer time. This extends the duration of the deviation of output from the steady state, i.e. it magnifies output persistence.

Under wage staggering, diminishing returns to labor (on an aggregate level) lead to larger deviations of prices from the old steady state in the impact period than constant returns. The reason is that prices are a mark-up over marginal costs, the marginal costs depend on the deviation of output from the steady state (under diminishing returns). Because of the instantaneous inflation jump during the impact period (see the inflation graph in Figure 4), the room for output adjustments will be reduced considerably and thus the wage-staggering mechanism will generate less persistence in terms of quantitative inertia than under constant returns to labor.

Although the New Keynesian literature often claims that wage staggering generates more plausible impulse response functions of output with respect to monetary shocks, our analysis sounds a cautionary note. First, as noted, wage staggering generates more output persistence only when the elasticities of substitution for labor and products are sufficiently close. Secondly, under firm-specific capital wage staggering has a lower inflation persistence than price staggering, either in terms of the contract multiplier or in terms of quantitative inertia (see the inflation graph in Figure 4).

The intuition above shows why a big part of the existing literature - resting on the assumption of constant returns to labor or homogenous capital - concludes that wage staggering generates more output persistence than price staggering. If the marginal disutility of labor function is assumed to be increasing with output, whereas the marginal cost curve is assumed to be flat and thus independent of the firm-specific output, then wage staggering turns out to lead to more output persistence than price staggering. But in the presence of diminishing returns to labor the output effects of the price-staggering mechanism are strengthened and thus the conventional result need no longer hold.

\subsubsection{Intuition on How Competitiveness Affects Monetary Persistence}

We now explain intuitively how the relative competitiveness of the labor and product markets influences monetary persistence. We measure relative competitiveness

\footnotetext{
${ }^{36}$ See Figure 5 in Altig et al. (2005) for a very nice graphical illustration.
} 
in terms of the relative elasticities of substitution among products and labor types. The greater the elasticity of substitution, the smaller is the individual wage rise (in the wage-staggering model) or price rise (in the price-staggering model) relative to the market average, in response to a positive monetary shock. Since demand fluctuations are undesirable for households and firms with respect to their utility and profit maximization, the degree of wage/price adjustment will be more muted. As result, the output response is more persistent.

This means that relative competitiveness matters for persistence. The more competitive the product market relative to the labor market, the greater is the monetary persistence generated by price staggering relative to that generated by wage staggering. If the labor market is calibrated in realistic manner, this will reduce the persistence of wage staggering compared to price staggering.

\section{The Interaction between Wage and Price Stag- gering}

While it is clearly important to analyze the interaction between wage and price staggering mechanisms since many medium-sized business cycle models (e.g., Altig et al., 2005, Christiano et al., 2005, Smets and Wouters, 2003) include both mechanisms, their complementarity has not as yet been examined. ${ }^{37}$ To do so, consider an economy where households and firms set both prices and wages in a staggered fashion. Specifically, households set staggered wages as mark-up over the current and future individual marginal rate of substitution and prices, and firms set staggered prices as mark-up over their current and future firm-specific marginal costs. The dynamic system for joint wage and price staggering comprises equations (19) - (24), (26), (30) and (33).

We measure the single-period complementarity between wage and price staggering, by dividing the output effects of joint wage and price staggering in period $t$ (denoted by $\hat{y}_{t, w+p}$ ) by the sum of the individual output of the two staggering types in period $t$ (the effects of wage and price staggering are denoted by $\hat{y}_{w}$ and $\hat{y}_{p}$ respectively): $\hat{y}_{t, w+p} /\left(\hat{y}_{t, w}+\hat{y}_{t, p}\right)$. A ratio larger than unity implies that wage and price staggering are complementary in period $t$, a ratio less than unity implies that they are substitutes.

\footnotetext{
${ }^{37}$ Note that Chari et al. (2002) show that adding wage staggering on top of price staggering increases consumption and GDP autocorrelations (see Table 6 in their paper). At first sight, the increases appear to be small. Note however that their autocorrelation measure is very similar to other speed of dying out measures which are only able to capture some aspects of persistence (see discussion in Section 3.3.2). Huang et al. (2004) find out that wage staggering, price staggering and a roundabout input-output structure are able to generate mildly procyclical real wages, as observed in the more recent data. However, they do not analyze complementarities either.
} 
In addition, we measure the complementarity or substitutability over a time interval by

$$
v_{\tau}=\frac{\psi_{\tau, w+p}}{\psi_{\tau, w}+\psi_{\tau, p}},
$$

where $\psi_{\tau, w+p}$ is the quantitative inertia (from period 1 to $\tau$ ) under joint wage and price staggering, $\psi_{\tau, w}$ and $\psi_{\tau, p}$ are the quantitative inertia under wage and price staggering respectively (from period 1 to $\tau$ ). Here $v_{\tau}>1$ implies that wage and price staggering are complementary over the time interval $[1, \tau]$, and $v_{\tau}<1$ implies substitutability. ${ }^{38}$

\subsection{Wage Price Interaction}

Under the chosen calibration for firm-specific capital ${ }^{39}$, the positive interaction between wage and price staggering reaches its peak about one and a half years after the shock, as shown in Figure 3. At this point, joint price and wage staggering generate around 20 percent more output than the sum of the two individual mechanisms (in terms of single-period complementarities). ${ }^{40}$ The figure also shows the interaction becomes less important after that.

Wage and price staggering interact in two ways:

1) Under wage staggering but no price staggering a monetary shock leads to a big inflation jump during the shock period, as the real wage and thus the marginal costs increase a lot (see Figure 4). If we now introduce price staggering into this model (i.e. if we have joint and wage staggering), the initial inflation jump will be much smaller than before, since a certain fraction of firms cannot adjust the prices immediately. The smaller price increase during the shock period means that it takes a longer time until the economy reaches its new steady state price level and leaves more room for after-shock output effects. As a consequence, quantitative inertia increases and complementarities are likely to show up.

\footnotetext{
${ }^{38}$ The complemenatarity measure is very much related to the quantitative inertia measure. With its sensitivity with respect to multiplicative shift it is well suited to explore complementarities between price and wage staggering (over time as well as in cumulative manner). In contrast, it would be extremely difficult to interpret the meaning of a complementarity measure, which is defined on basis of ratios (such as the contract multiplier) when the output IRFs start out with completely different impact effects (as it is the case for the calibrated model economies, see Figure 2).

${ }^{39}$ In line with the previous Section, we choose $\kappa=0.04, \theta_{w}=0.5$, and $\varepsilon_{w}=2$.

${ }^{40}$ The pattern of complementarities is similar for the chosen calibrations. However, the degree of complementarities depends on the values for the deep parameters. As will be discussed below, the overall complementarities are even bigger under homogenous capital than under firm-specific capital.
} 
2) Under joint price and wage staggering the real wage adjustment is a lot more sluggish than under flexible wages, as the dynamics in the labor market are governed by the Calvo adjustment mechanism (see Figure 4). Thus, firms' marginal costs pressure is reduced considerably under joint staggering (compared to price staggering) and this reduces the inflation rate in the respective period (see equation (30)). Consequently, there is an intertemporal wage-price spiral: the slower wages adjust, the slower prices adjust, and vice versa (see equation (26)). This reduces the output's speed of dying out under joint wage and price staggering. Therefore, the single-period complementarities between wage and price staggering increase with the passage of time (see Figure 3).

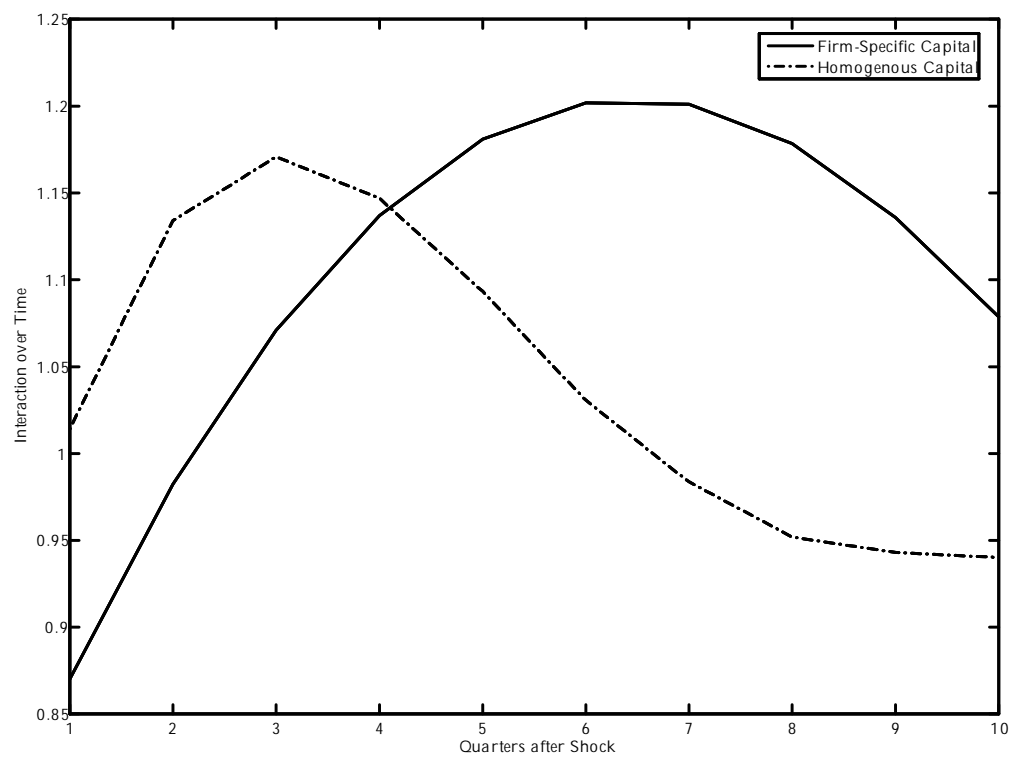

Figure 3: Interaction between wage and price staggering over time (single-period complementarities).

However, the interaction between wage and price staggering causes the marginal costs only in the short-run to rise more slowly than with flexible wages. Once the real marginal costs have peaked, the interaction between wage and price staggering causes the real marginal costs to fall more slowly than they would under flexible wages and consequently the single-period complementarities diminish through time. ${ }^{41}$

\footnotetext{
${ }^{41}$ However, the peak in marginal costs does not correspond to the peak in output complementarities (see Figures 3 and 4). One of the underlying reasons is the investment activity. It
} 
Wage and price staggering turn out to be complementary over the horizon from the first period to the infinite future. Over the medium-run, which is the relevant time-span for these models and which we define as 2.5 years, joint wage and price staggering generate 4 percent ${ }^{42}$ more quantitative inertia than the sum of the individual mechanisms $\left(v_{10}=1.04\right) .{ }^{43}$
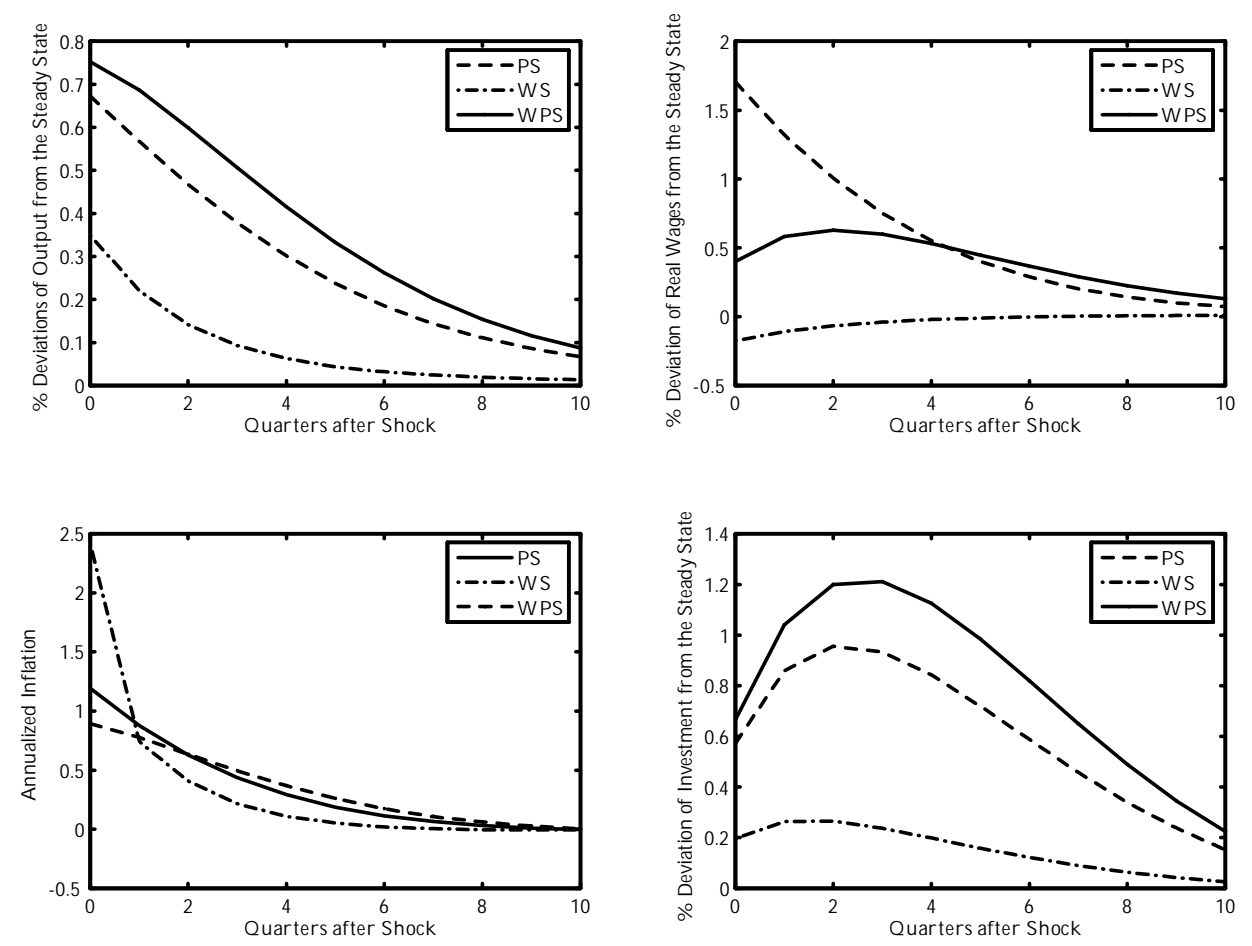

Figure 4: IRFs for price staggering $(\kappa=0.04)$, wage staggering $\left(\theta_{w}=0.5, \varepsilon_{w}=2\right)$, and joint wage and price staggering under firm-specific capital accumulation .

is highly complementary, particulary in the medium-run (see Figure 4). Thereby, the capital accumulation under joint wage and price staggering is stimulated and the medium-run output complementarities are strenghtened (via the production function, see equation (22)).

${ }^{42}$ This number does not change a lot for the infinite horizon. If we measure it for 100 quarters after the shock, $v_{100}=1.03$.

${ }^{43}$ Note that under the chosen range of calibrations wage and price staggering are not complementary in terms of the contract multiplier. However, the sum of two ratios (which are possibly measured on basis of very different impact effects, as it is the case for our models) is very difficult to interpret. In any case, as discussed above, the contract multiplier and quantitative inertia measure two different aspects of persistence. 


\subsection{Importance of Complementarities}

Under homogenous capital accumulation complementarities show up immediately after the shock has disappeared (see Figure 3). The joint wage-price staggering mechanism generates 17 percent more output at its peak than the individual mechanisms (single-period complementarities). However, the positive interaction between wage and price staggering also disappears more quickly. As monetary shocks generate the largest part of the output effects in the short-run, the overall size of complementarities turns out to be bigger under homogenous capital than under firm-specific capital accumulation (where the positive interaction kicks in later). Over the medium-run (10 quarters) quantitative inertia is 7 percent bigger for joint wage and price staggering than for the sum of the individual mechanisms $\left(v_{10}=1.07\right)$.

The more substantial complementarities under homogenous capital accumulation are linked to the persistence of the underlying price staggering mechanisms: It was shown in Section 3 that the output persistence of an economy with staggered prices and flexible wages is less persistent under homogenous capital accumulation than under firm-specific capital accumulation. The connection between monetary persistence and complementarities can most easily be illustrated by the log-linearized Phillips curve $\left(\hat{\pi}_{t}=\beta E_{t} \hat{\pi}_{t+1}+\kappa \widehat{m c_{t}^{r}}\right)$ : Under homogenous capital (which corresponds to a higher $\kappa$ if all other deep parameter stay the same) the current inflation rate $\left(\hat{\pi}_{t}\right)$ is more sensitive to the economy's marginal costs pressure than under firm-specific capital. If staggered wages are added on top of staggered prices, the marginal cost pressure is reduced. Due to the bigger $\kappa$ this is translated more directly into a lower inflation pressure under homogenous than under firmspecific capital. Thus, the two described effects, which cause complementarities (reduction of the inflation jump during the shock period and the intertemporal wage-price spiral, see Section 4.1), are stronger.

Along the same lines, it is true that the overall complementarities increase, the higher the frequency of price changes is (i.e. the larger the probability of re-adjusting the price, $1-\theta_{p}$, which also increases the parameter $\left.\kappa\right) .{ }^{44}$ This is an important finding in light of the so called micro-macro conflict. While microeconometric studies indicate a low degree of price stickiness (i.e. high frequency of price adjustment), macroeconometric models need a high degree of price stickiness in order to match the empirical reaction to shocks (e.g., Altig et al., 2005, and Bils and Klenow, 2004). As a consequence, the interaction between wage and price staggering turns out to be an important mechanism to generate additional persistence, particularly under a high frequency of price adjustment.

\footnotetext{
${ }^{44}$ Numerical results are available on request.
} 


\section{Relation to the Literature}

There is a relatively large body of literature on the relative degree of monetary persistence arising from wage and price staggering under Taylor contracts, but relatively little under Calvo contracts (the focus of this paper), although the latter are more common in the recent literature.

As noted, the recent literature on Taylor contracts concludes that wage staggering generates more monetary persistence than price staggering. In Andersen's (1998) model output responses from wage staggering are always longer lived than from price staggering. In Huang and Liu's (2002) paper the output responses from price staggering are dampened oscillatory, whereas the output IRFs from wage staggering are not. ${ }^{45}$ The oscillatory output response to monetary shocks for Taylor contracts under the standard numerical calibrations in dynamic stochastic general equilibrium (DSGE) models (Kiley, 1997, Chari et al., 2000, Huang and Liu, 2002) is considered an important weakness of the Taylor model.

Many authors have sought to overcome persistence problems by incorporating real rigidities in price-staggering models. But the contributions were very much focussed on the labor market side. Ascari (2003) points out the role of sectoral labor mobility on monetary persistence. Edge (2002) assumes firm-specific factor inputs (both labor and capital) to restore the equivalence of wage and price staggering, i.e. that each household is coupled with a firm, hiring its labor and capital out to that firm only. ${ }^{46}$ Jeanne (1998) introduces a real wage rigidity, as unions may be concerned about a fair division of income between labor and capital. Kiley (1997) analyzes the effect of several real rigidities to increase the persistence of price staggering, such as countercyclical mark-ups. The basic insight goes back to Blanchard and Fischer (1989) and Ball and Romer (1990), who argue that it is necessary to flatten the supply side in order to prevent procyclical marginal costs, which would lead to fast price adjustments and thus low persistence.

Taylor (1999) observed that "there needs to be some neighborhood effects between price setters, so that one firm pays attention to the price decision of the next firm and the most recent firm, thereby linking the price decision of one firm to another and causing the persistence effects." This phenomenon applies to the price-staggering model under firm-specific capital. Firms pay more attention to their relative price from a purely profit-maximizing perspective. If the firm-specific price is too far above the average market price, there will be undesirable demand fluctuations.

\footnotetext{
${ }^{45}$ Erceg (1997) uses both types of staggering, which can account for a strong contract multiplier.

${ }^{46}$ The basic idea to slow down price adjustments with real rigidities in a DSGE model with nominal rigidities was first proposed by Kimball (1995) and implemented by Rotemberg (1996). In a unifying framework Ascari (2003) shows that labor immobility plays a key role in generating persistence.
} 
Regarding Calvo contracts (as in our paper), various contributions examine how realistically Calvo wage and/or price staggering can replicate empirical impulse response functions or how optimal monetary policy has to be conducted in such a framework. ${ }^{47}$ To the best of our knowledge, however, the only study that explicitly ${ }^{48}$ discusses the differences in persistence generated by Calvo wage and price staggering is Kim (2003). He states that in contrast to Taylor contracts, Calvo wage and price staggering can both generate persistence (no oscillatory movements). But similar to the studies for Taylor staggering, he concludes that wage staggering is generally better able to generate persistence. We confirm the first result, but have doubts about the second because it hinges on the assumption of homogenous capital accumulation.

The recent contributions on firm-specific capital (Altig et al., 2005, Sveen and Weinke, 2005, 2007, Woodford, 2005) allow us to shed new light on the relative persistence of wage and price staggering, which has so far not been discussed in the literature. Furthermore, the inability to explain sufficient inflation persistence is known to be a major weakness of New Keynesian models (see, for example, Fuhrer and Moore, 1995, Mankiw, 2001). Our paper contributes to this literature by showing and explaining the intuition why wage staggering under decreasing returns has a low inflation persistence, either measured in terms of the contract multiplier or in terms of "quantitative inertia" (see Section 3.4.2).

The existing literature uses the contract multiplier to measure output persistence from numerical impulse response functions (see e.g. Huang and Liu, 2002, Kim 2003). The weaknesses of this measure have not been discussed to date. This paper does so and introduces the quantitative inertia measure to address this problem.

The complementarities of wage and price staggering in generating persistence have not been examined in the literature; our "quantitative inertia" measure enables us to do so in a meaningful way. We show that wage and price staggering are complementary. The interactions are strongest in the short- and medium-run, which is the relevant time span for business cycle modelers, and deliver around 20 percent additional output in their peak (in terms of single-period complementarities).

\footnotetext{
${ }^{47}$ To mention just a few examples: Rotemberg and Woodford (1998) try to match empirical impulse response functions with a Calvo price staggering model. Christiano et al. (2005) have the same objective. Gali (2003) derives impulse response functions from Calvo price staggering and discusses optimal monetary policy. Erceg et al. (2000) use a model with Calvo wage and price staggering that is similar in spirit to ours. They do not discuss the issue of monetary persistence, but optimal monetary policy.

${ }^{48}$ Christiano et al. (2005), who match the empirical from a Var and their model's theoretical IRFs, shortly discuss the relative persistence of wage and price staggering and come to the same conclusion as Kim (2003).
} 


\section{Concluding Thoughts}

This paper shows that under firm-specific capital the relative degree of competition in the labor and product markets plays a central role in determining the relative monetary persistence arising from wage and price staggering. The less competitive the labor market is relative to the product market, the less persistent will be the output responses to a monetary shock arising from the wage inertia relative to the price inertia. Thus, under reasonable calibrations wage staggering generates less persistence than price staggering.

In addition, we find that wage and price staggering have complementary effects on monetary persistence. We show this in terms of a new measure of monetary persistence, which we have called "quantitative inertia." The existence of complementarities means that beyond understanding how wage and price staggering work in isolation, it is important to explore their interactions. 


\section{References}

Altig, David, Lawrence Christiano, Martin Eichenbaum and Jesper Linde (2005) Firm-specific capital, nominal rigidities and the business cycle. NBER Working Paper 11034.

Andersen, Torben M. (1998) Persistency in sticky price models. European Economic Review 42 (3), 593-603.

Ascari, Guido (2003) Price/wage staggering and persistence: a unifying framework. Journal of Economic Surveys 17 (4), 511-540.

Ball, Laurence and David Romer (1990) Real rigidities and the non-neutrality of money. Review of Economic Studies 57 (2), 183-203.

Barro, Robert J. (1977) Long-term contracting, sticky prices, and monetary policy. Journal of Monetary Economics 3, 305-316.

Bils, Mark and Peter J. Klenow (2004) Some evidence on the importance of sticky prices. Journal of Political Economy 112 (5), 947-985.

Blanchard, Olivier.J. and Stanley Fischer (1989) Lectures on macroeconomics. Cambridge, MA: MIT Press.

Blanchard, Olivier J. and Nobuhiro Kiyotaki (1987) Monopolistic competition and the effects of aggregate demand. American Economic Review 77 (4), 647-666.

Bowman, David (2003) Market Power and Inflation. International Finance Discussion Papers 783.

Calvo, Guillermo A. (1983) Staggered prices in a utility maximizing framework. Journal of Monetary Economics 12 (3), 383-398.

Chari, V.V., Patrick J. Kehoe and Ellen R. McGrattan (2002) Can sticky price models generate volatile and persistent real exchange rates? Review of Economic Studies 69 (3), 533-563.

Chari, V.V., Patrick J. Kehoe and Ellen R. McGrattan (2000) Sticky price models of the business cycle: can the contract multiplier solve the persistence problem. Econometrica 68 (5), 1151-1179.

Christiano, Lawrence J., Martin Eichenbaum and Charles Evans (2005) Nominal rigidities and the dynamic effects of a shock to monetary policy. Journal of Political Economy 113 (1), 1-45. 
Dixit, Avinash K. and Joseph E. Stiglitz (1977) Monopolistic competition and optimum product diversity. American Economic Review 67 (3), 297-308.

Dobson, Paul W. (1997) Union-firm interaction and the right to manage. Bulletin of Economic Research 49 (3), 213-229.

Edge, Rochelle M. (2002) The equivalence of wage and price staggering in monetary business cycle models. Review of Economic Dynamics 5 (3), 559-585.

Eichenbaum, Martin and Jonas D.M. Fisher (2004) Evaluating the Calvo model of sticky prices. NBER Working Paper 10617.

Erceg, Christopher J. (1997) Nominal wage rigidities and the propagation of monetary disturbances. International Finance Discussion Papers 590.

Erceg, Christopher J., Dale W. Henderson and Andrew T. Levin (2000) Optimal monetary policy with staggered wage and price contracts. Journal of Monetary Economics 46, 281-313.

Fuhrer, Jeff and George Moore (1995) Inflation Persistence. Quarterly Journal of Economics 110 (1), 127-159.

Gali, Jordi (2003) New perspectives on monetary policy, inflation, and the business cycle. In Mathias Dewatriport, Lars Peter Hansen and Stephen J. Turnovsky (eds.), Advances in Economics and Econometrics: Theory and Applications, pp. 151-197. Cambridge, MA: Cambridge University Press.

Gali, Jordi, Mark Gertler and David López-Salido (2003) Markups, gaps, and the welfare costs of business fluctuations. CEPR Working Paper 4134.

Griffin, Peter (1992) The impact of affirmative action on labor demand: a test of some implications of the Le Chatelier principle. Review of Economics and Statistics 74 (2), 251-260.

Huang, Kevin X. D., Zheng Liu and Louis Phaneuf (2004) Why does the cyclical behavior of real wages change over time? American Economic Review 94 (4), 836-856.

Huang, Kevin X. D. and Zheng Liu (2002) Staggered price-setting, staggered wage setting, and business cycle persistence. Journal of Monetary Economics 49 (2), 405-433.

Jeanne, Olivier (1998) Generating real persistent effects of monetary shocks: how much nominal rigidity do we really need? European Economic Review 42 (6), 1009-1032. 
Kiley, Michael T. (1997) Staggered price setting and real rigidity. Federal Reserve Board Working Paper 46.

Kim, Jangryoul (2003) Contract multiplier revisited: solving the persistence problem in a model with staggered contracts. Federal Reserve Bank of Minneapolis, Banking and Policy Working Paper 1-03, February 2003.

Kimball, Miles S. (1995) The quantitative analytics of the basic neomonetarist model. Journal of Money, Credit, and Banking 27, 1241-1277.

Mankiw, Gregory N. (2001) The inexplorable and mysterious tradeoff between inflation and unemployment. The Economic Journal 111, 45-61.

Merkl, Christian and Dennis Snower (2007) Monetary persistence, imperfect competition, and staggering complementarities. Kiel Working Paper 125\%, revised version: July 2007.

Rotemberg, Julio J. (1996) Prices, output, and hours: an empirical analysis based on a sticky price model. Journal of Monetary Economics 37 (3), 505-533.

Rotemberg, Julio J. and Michael Woodford (1998) An optimization-based econometric framework for the evaluation of monetary policy: expanded version. NBER Technical Working Papers 0233.

Sbodorne, Argia M. (2002) Prices and unit labor costs: a new test of price stickiness. Journal of Monetary Economics 49 (2), 265-292.

Smets, Frank and Rafael Wouters (2003) An estimated dynamic stochastic general equilibrium model of the Euro area. Journal of the European Economic Association 1 (5), 1123-1175.

Sveen, Tommy and Lutz Weinke (2007) Firm specific capital, nominal rigidities, and the Taylor principle. Journal of Economic Theory, forthcoming.

Sveen, Tommy and Lutz Weinke (2005) New perspectives on capital, sticky prices, and the Taylor principle. Journal of Economic Theory 123 (1), 21-39.

Taylor, John B. (1999) Staggered price and wage setting in macroeconomics. In: John B. Taylor and Michael Woodford (eds.), Handbook of Macroeconomics Vol. 1B., pp. 1009-1050. Amsterdam: Elsevier.

Taylor, John B. (1980) Aggregate dynamics and staggered contracts. Journal of Political Economy 88 (1), 1-23.

Woodford, Michael (2005) Firm-specific capital and the New-Keynesian Phillips curve. International Journal of Central Banking 1 (2), 1-46. 


\section{Appendix: Time Varying Speed of Dying Out}

The speed of dying out of the different models varies considerably over time (see Figure 5). Thus, persistence comparisons which are based on the speed of dying out may lead to very different results. If the wage staggering output IRF (with $\varepsilon_{w}=10$ ) and the price staggering IRF (with $\kappa=0.04$ ) are compared on basis of the half-life measure, they are similarly persistent (3 to 4 quarters in both cases). In contrast, it takes between 18 and 19 quarters until the output deviations shrink to 5 percent of the impact effect under wage staggering, while this is the case between period 14 and 15 under price staggering.

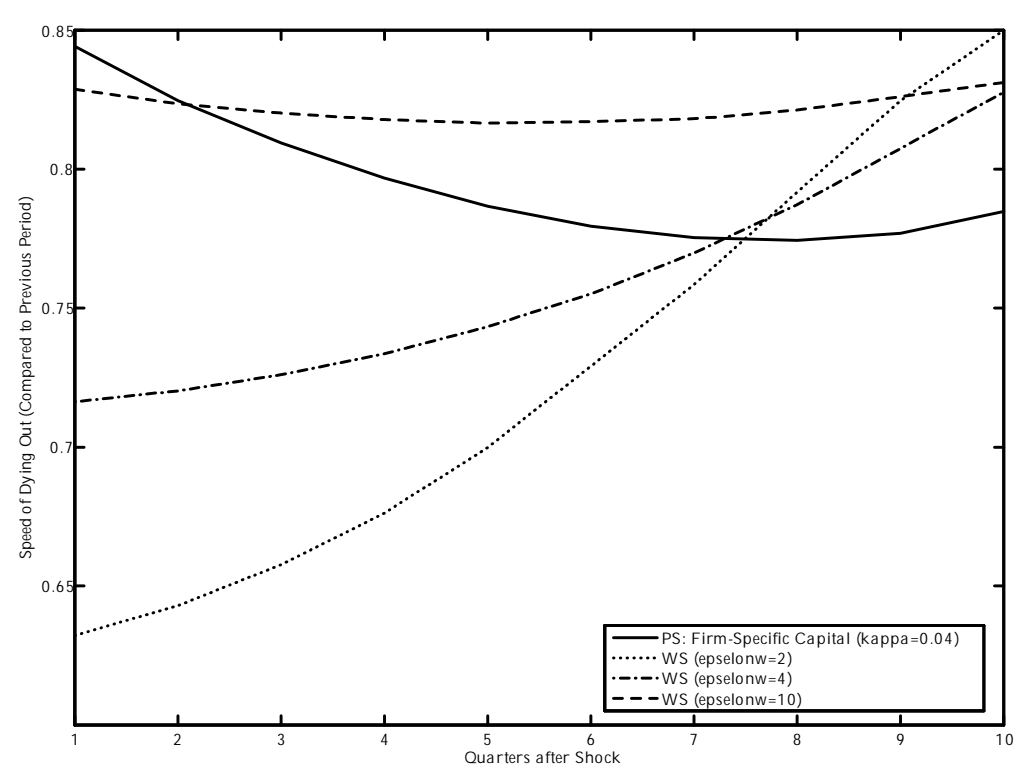

Figure 5: Speed of dying out over time 